\title{
Shape Memory Effect in Cast Versus Deformation-Processed NiTiNb Alloys
}

\author{
Reginald F. Hamilton ${ }^{1}$ - Asheesh Lanba ${ }^{1}$ - Osman E. Ozbulut ${ }^{2} \cdot$ Bernhard R. Tittmann $^{1}$
}

Published online: 7 July 2015

(C) ASM International 2015

\begin{abstract}
The shape memory effect (SME) response of a deformation-processed NiTiNb shape memory alloy is benchmarked against the response of a cast alloy. The insoluble $\mathrm{Nb}$ element ternary addition is known to widen the hysteresis with respect to the binary NiTi alloy. Cast microstructures naturally consist of a cellular arrangement of characteristic eutectic microconstituents surrounding primary matrix regions. Deformation processing typically aligns the microconstituents such that the microstructure resembles discontinuous fiber-reinforced composites. Processed alloys are typically characterized for heat-to-recover applications and thus deformed at constant temperature and subsequently heated for SME recovery, and the critical stress levels are expected to facilitate plastic deformation of the microconstituents. The current work employs thermal cycling under constant bias stresses below those critical levels. This comparative study of cast versus deformation-processed NiTiNb alloys contrasts the straintemperature responses in terms of forward $\Delta T_{\mathrm{F}}=M_{\mathrm{s}}-M_{\mathrm{f}}$ and reverse $\Delta T_{\mathrm{R}}=A_{\mathrm{f}}-A_{\mathrm{s}}$ temperature intervals, the thermal hysteresis, and the recovery ratio. The results underscore that the deformation-processed microstructure inherently promotes irreversibility and differential forward and reverse transformation pathways.
\end{abstract}

Reginald F. Hamilton

rfhamilton@psu.edu

1 Department of Engineering Science and Mechanics, The Pennsylvania State University, 212 Earth-Engineering Sciences Building, University Park, PA 16802, USA

2 Department of Civil and Environmental Engineering, University of Virginia, Charlottesville, VA 22901, USA
Keywords NiTiNb shape memory alloys (SMAs) . Thermal hysteresis - Deformation processing - Shape memory effect

\section{Introduction}

NiTiNb alloys are a class of NiTi-based shape memory alloys (SMAs) distinguished by microconstituent morphologies that facilitate a wide thermal hysteresis, more than triple that of conventional NiTi SMAs. The wider hysteresis is a result of stark increases in the reverse transformation temperatures $A_{\mathrm{s}}$ and $A_{\mathrm{f}}$ during shape memory effect (SME) recovery after martensite deformation [1-13]. Those general observations were correlated to the microstructure for heat-to-recover applications (mainly couplings) in the inaugural works of Melton et al. [1,2]. The influence of $\mathrm{Nb}$ addition to NiTi with respect to plastic deformation giving rise to the wide hysteresis has been expounded upon by Zhang et al. [3, 4], Zhao et al. [5-10], and Piao et al. [11-13]. More recently, the NiTiNb classes of SMAs have garnered interests due to the wide hysteresis levels matching operating temperatures for civil engineering applications requiring pre-stressing or constraint stressing [14-19]. Furthermore, the materials are expected to exhibit damping potential $[20,21]$ as well as good oxidation resistance [22].

The NiTiNb alloys are typically cast and subsequently thermomechanically deformation-processed into useful forms such as wires, rods, or sheets for practical application [23]. As-cast microstructures generally consist of $\beta$ $\mathrm{Nb}+$ eutectic NiTi (with dissolved $\mathrm{Nb}$ ) in a cellular configuration surrounding primary $\mathrm{NiTi}$ (with dissolved $\mathrm{Nb}$ ) matrix material, consistent with characteristic eutectic microconstituent phases $[3,5,9,12,18,21,24-31]$. 
Several investigations characterize the impact of deformation processing conditions on the microstructure $[19,25$, 31-35]. Ultimately, the findings show that the deformationprocessed microstructure is made up of oriented $\beta-\mathrm{Nb}$-rich microconstituents that are dispersed throughout the matrix similar to aligned discontinuous fiber (or nanowire)-reinforced composites [36-38].

The functionality of deformation-processed NiTiNb materials is primarily investigated via isothermal prestraining deformation of an initially martensitic or austenitic microstructure and subsequent assessment of SME recovery via heating $[1,4,9,13,18,26,27,39]$. Transformation strain recovery during heating is typically characterized without load or under displacement constraint to assess the recovery stresses. The $\beta-\mathrm{Nb}$ phase is presumably soft, and the critical stresses during isothermal pre-straining deformation are expected to plastically deform them, presuming that their flow stress matches that for pure $\mathrm{Nb}$ which is estimated between 150 and $200 \mathrm{MPa}$ [1, 2, 23]. Plastic deformation of microconstituents as martensite deforms necessitates an increased thermal driving force for the reverse transformation that results in elevated $A_{\mathrm{s}}$ and $A_{\mathrm{f}}$ temperatures and the wide hysteresis $[1,2,4,13,30]$, commonly referred to as a stabilization effect [4, 10, 40-42].

The current work is an original investigation of the oneway strain-temperature $(\varepsilon-T)$ response. Constant bias load levels are applied during thermal cycling, and the levels are incrementally increased up to those reported to facilitate plastic deformation of Nb-rich microconstituents. Moreover, this is the first comparative study of cast versus deformation-processed NiTiNb alloys. Only the matrix undergoes the martensitic transformation (MT) and hence exhibits SME. In the cast alloy, large matrix regions exist without the obvious appearance of microconstituent phases within the regions. However, within the composite-like deformation-processed microstructure, $\beta-\mathrm{Nb}$ fibers are dispersed throughout the matrix and presumably can interact differently with the MT morphology compared to the cast microstructure. The aim of this comparative study is to gain insights into the impact of $\beta-\mathrm{Nb}$-rich phase using the cast material $\varepsilon-T$ response as a benchmark for the deformation-processed material response, which is the prototypical NiTiNb SMA microstructure.

\section{Materials and Methods}

The compositions of both alloys are nearly equal to $\mathrm{Ni}_{47}$ $\mathrm{Ti}_{44} \mathrm{Nb}_{9}$ at.\%, which is the recommended ternary composition for wide hysteresis applications [23]. Atlantic Metals and Alloys LLC supplied a cast alloy with the composition $\mathrm{Ni}_{47.3} \mathrm{Ti}_{44.1} \mathrm{Nb}_{8.6}$ at.\%. Medical Metals LLC supplied a deformation-processed sheet with the composition
$\mathrm{Ni}_{47.7} \mathrm{Ti}_{43.5} \mathrm{Nb}_{8.8}$ at.\%. The thermo-mechanical processing methods for the strip are multiple thickness reductions using cold work via rolling and annealing near the recrystallization temperature $\left(850^{\circ} \mathrm{C}\right)$. Tensile specimens with dog-bone geometry were electrical discharge machined (EDM) from the cast materials. The gage dimensions were length $(l)=10 \mathrm{~mm}$, width $(w)=3 \mathrm{~mm}$, and thickness $(t)=1 \mathrm{~mm}$. The thickness of the deformation-processed sheet material was $t=0.25 \mathrm{~mm}$, and EDM was utilized to micromachine dog-bone specimens with $l=10 \mathrm{~mm}$ and $w=3 \mathrm{~mm}$.

Specimens were mechanically polished for scanning electron microscopy (SEM) and atomic force microscopy (AFM) analysis. The materials were polished via $\mathrm{SiC}$ paper with the grit size decreasing from 180 to 1200 and finally polished using $0.02-\mu \mathrm{m}$ colloidal silica. Microstructural images were taken at room temperature using a Philips XL30 ESEM scanning electron microscope. For higher magnification imaging, a FEI NanoSEM 630 scanning electron microscope was employed. SEM imaging was performed in back-scattered electron mode. A Veeco Metrology Autoprobe M5 atomic force microscope (AFM) was used in contact mode and in air. The contact force was maintained around $10-20 \mathrm{nN}$ with an imaging frequency of $1 \mathrm{~Hz}$ and a minimum detectable surface feature height of $1.2 \AA$.

Load-biased thermal cycling experiments were conducted using an MTS 810 servo-hydraulic load frame equipped with a customized temperature cycling set-up. Temperature gradients within the specimen were minimized, and the heating and cooling rates were within $5-10{ }^{\circ} \mathrm{C} / \mathrm{min}$. The specimens were first heated to $150{ }^{\circ} \mathrm{C}$, to ensure that the specimens were in the austenitic state. The desired bias load was then applied and held constant. The specimens were cooled to $-90{ }^{\circ} \mathrm{C}$ and then heated to $150{ }^{\circ} \mathrm{C}$. The external load for successive thermal cycles was increased incrementally between 10 and $300 \mathrm{MPa}$. The strain was calculated based on the displacement of the actuator.

\section{Results}

\section{Microstructure Characterization}

Figures 1, 2 and 3 show the SEM micrographs of the cast and deformation-processed microstructures. The cast microstructure in Fig. 1a, b exhibits the hypoeutectic character; the characteristic eutectic microconstituent is arranged in a cellular configuration as boundaries encompassing regions of $\mathrm{NiTi}(\mathrm{Nb})$ matrix. The AFM image in Fig. 1c reveals topography of the matrix and cellular eutectic microconstituent. Locally, between the matrix and 

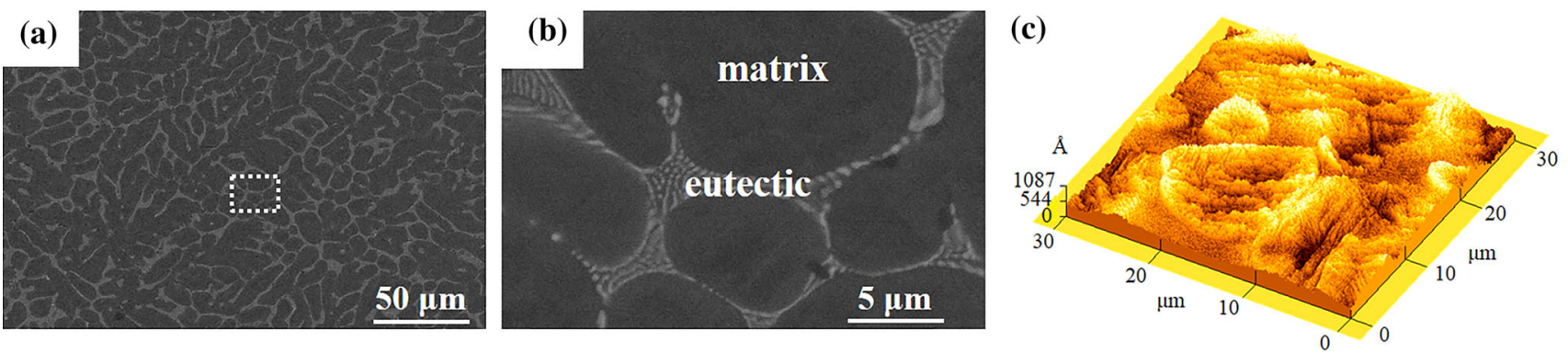

Fig. 1 a SEM micrograph of the cast alloy cellular eutectic microconstituent arrangement, b SEM micrograph of the matrix encompassed by the eutectic in the region within the box in a, c. 3D AFM image showing the varying surface topology
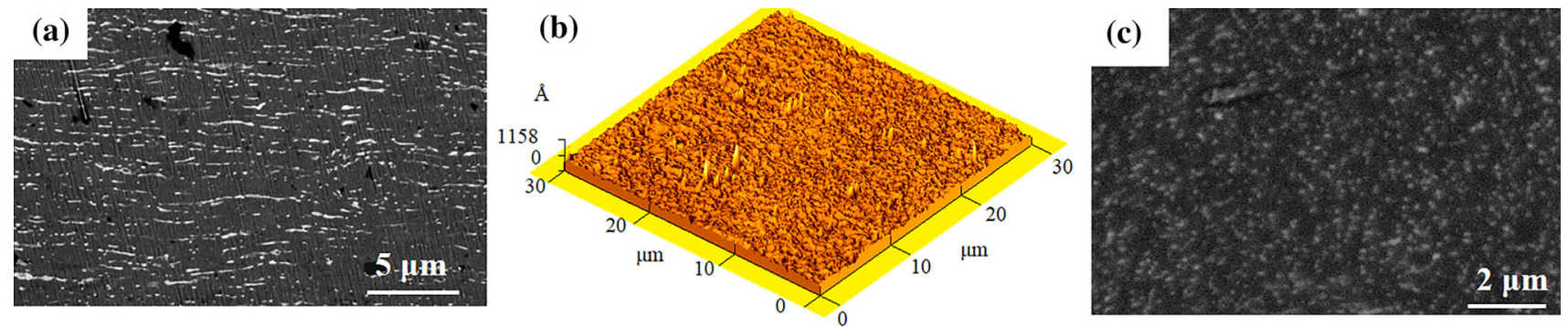

Fig. 2 a SEM micrograph of the deformation-processed microstructure with the Nb-rich fibers oriented in the rolling direction, b 3D AFM image of the smooth surface and c SEM micrograph of the transverse-section of the composite fibers

Fig. 3 High-magnification SEM micrographs of the a eutectic microconstituent phases in the cast microstructure and $\mathbf{b}$ fibers with nano-scale dimensions in the deformationprocessed microstructures
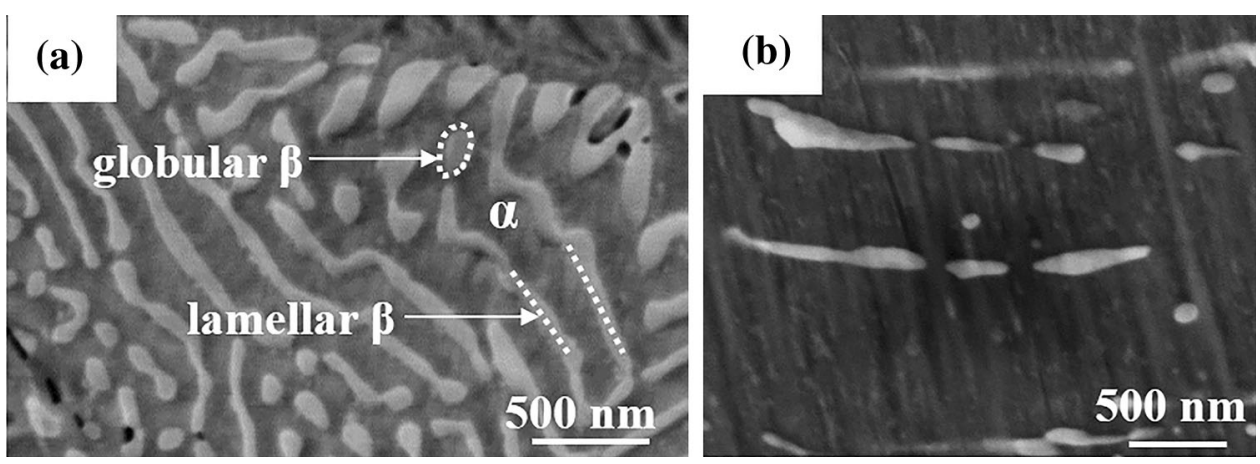

eutectic, well-defined boundaries exist and the cellular regions are raised. The centers of $\mathrm{NiTi}(\mathrm{Nb})$ matrix regions are the lowest height. Moving outward toward the eutectic, the height rises approaching the eutectic-matrix boundary. The height within the eutectic is relatively uniform. Figure $2 \mathrm{a}$ illustrates that the Nb-rich fibers are dispersed throughout the matrix and oriented in the processing directions, thus they appear as striations. The AFM images of the deformation-processed material are shown in Fig. 2b. The images reveal markedly refined topography that is relatively smooth compared to Fig. 1c. Figure 2c shows the transverse-section in which fibers appear as speckles with spacing on the order of $100 \mathrm{~nm}$. Figure $3 \mathrm{a}$ exposes the characteristic eutectic lamellar and globular mixture of $\mathrm{Nb}$-rich $\beta$-phase and $\alpha$-NiTiNb that is typical of dissolved $\mathrm{Nb}[3,5,9,12,18,21,24-31]$. The Nb-rich fibers in the deformation-processed material are aligned and discontinuous in Fig. 3b, yet the sizes remain consistent with those in Fig. 3a.

\section{Thermal Cycling With or Without Load}

The thermal-induced martensitic transformation (TIMT) during thermal cycling without load was evident for the cast material in Fig. 4. The TIMT brings about exothermic and endothermic events during cooling and heating respectively, and thus, peaks arise in the heat flow versus temperature thermograms measured using differential scanning calorimetry (DSC) analysis. TIMT temperatures were $M_{\mathrm{s}}=-63.6^{\circ} \mathrm{C}$, $M_{\mathrm{f}}=-106.4{ }^{\circ} \mathrm{C}, A_{\mathrm{s}}=-81.3{ }^{\circ} \mathrm{C}$, and $A_{\mathrm{f}}=11.4{ }^{\circ} \mathrm{C}$. For the deformation-processed material, however, evidence for the TIMT is not apparent in the DSC analysis.

The strain-temperature $(\varepsilon-T)$ responses in Fig. 5 show the one-way shape memory effect behavior for cast and 


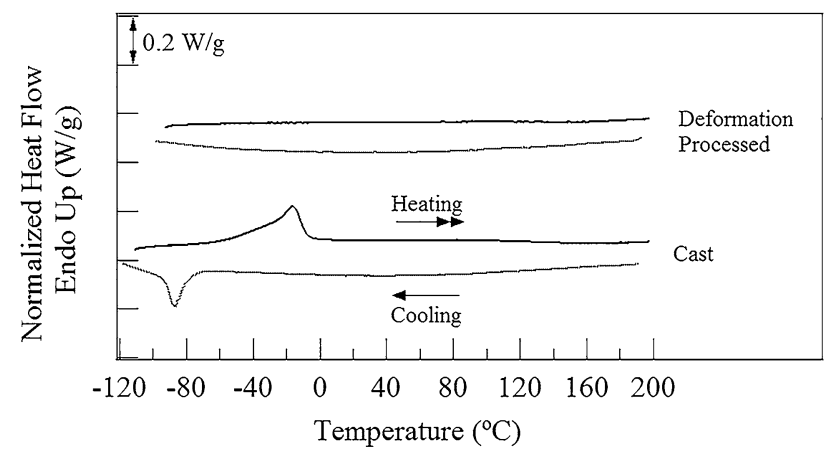

Fig. 4 Normalized heat flow versus temperature thermograms from differential scanning calorimetry analysis

deformation-processed alloys at increasing constant bias stress levels. A $\varepsilon-T$ response for the $100 \mathrm{MPa}$ bias load level is evident for the cast material in Fig. 5a. A bias load of $150 \mathrm{MPa}$ was needed for the processed material in Fig. 5b. Those bias stress levels were the minimum levels that brought about measurable transformation strain. The $M_{\mathrm{s}}$ temperatures for those bias stress levels for both materials are equivalent and approximately equal to $-67{ }^{\circ} \mathrm{C}$. For 100 and $150 \mathrm{MPa}$ bias stress levels applied to the cast materials, the slopes for the heating and cooling segments of the $\varepsilon-T$ curves are nearly equal. At $300 \mathrm{MPa}$, the slope for the heating segment differs from the cooling segment in Fig. 5a. For the deformation-processed alloy loaded at $150 \mathrm{MPa}$ in Fig. 5b, the slopes for both curves are equivalent. The slopes of the $300 \mathrm{MPa}$ cooling and heating $\varepsilon-T$ curves, however, exhibit differential slopes. Moreover, each curve exhibits two slopes. An initial slope appears vertical, and the stage is seemingly isothermal. A second different slope follows in the cooling $\varepsilon-T$ curve. The heating curve exhibits multiple slopes, albeit an isothermal stage is indiscernible.

Metrics that characterize the $\varepsilon-T$ response are plotted with increasing bias load in Fig. 6. Figure 6a captures the effect of bias stress on the forward transformation temperature interval $\Delta T_{\mathrm{F}}=M_{\mathrm{s}}-M_{\mathrm{f}}$ and the reverse interval $\Delta T_{R}=A_{\mathrm{f}}-A_{\mathrm{s}}$. For each material condition, the $\Delta T_{\mathrm{F}}$ is less than $\Delta T_{\mathrm{R}}$. The deformation-processed material exhibits the narrowest $\Delta T_{\mathrm{F}}$. The $\Delta T_{\mathrm{F}}$ for the cast material is over $30{ }^{\circ} \mathrm{C}$ higher. The reverse transformation finish temperature $A_{\mathrm{f}}$ exhibits a marked increase (greater than $80^{\circ} \mathrm{C}$ ) when the bias load is increased from 150 to $300 \mathrm{MPa}$ (see Fig. 5). Consequently, for both materials, the $\Delta T_{\mathrm{R}}$ increases (by nearly $60{ }^{\circ} \mathrm{C}$ ) from the lowest to highest bias load. The dependencies of thermal hysteresis and recovery ratio on bias stress level are illustrated in Fig. 6b. The thermal hysteresis $\Delta T_{\mathrm{H}}$ is determined as the temperature differential at half the recovered strain during heating (see Fig. 5). The hysteresis widens most when the stress is increased from 150 to $300 \mathrm{MPa}$. The recovery ratio equals $\left[\left(\varepsilon_{\mathrm{tr}}-\right.\right.$ $\left.\varepsilon_{\text {irr }}\right) / \varepsilon_{\text {tr }} \times 100$ ], where $\varepsilon_{\text {tr }}$ is the tensile strain accrued in the cooling $\varepsilon-T$ curve and $\varepsilon_{\text {irr }}$ is the unrecovered strain after heating (see Fig. 5). The $150 \mathrm{MPa}$ bias stress level facilitates a maximum recovery ratio for both materials and the ratio drops for the $300 \mathrm{MPa}$ level.

\section{Discussion}

The current findings demonstrate that despite vastly different microconstituent morphologies, plastic deformation of the $\beta-\mathrm{Nb}$-rich phase can have similar impacts on the strain-temperature characteristic metrics for cast and deformation-processed materials. In the NiTiNb class of NiTi-based SMAs, the NiTi composition is expected to dictate the transformation temperatures [1-4, 23]. Indeed, the current results for similar $\mathrm{Ni}_{47.3} \mathrm{Ti}_{44.1} \mathrm{Nb}_{8.6}$ at.\% (cast) and $\mathrm{Ni}_{47.7} \mathrm{Ti}_{43.5} \mathrm{Nb}_{8.8}$ at.\% (deformation-processed) compositions exhibit equivalent $M_{\mathrm{s}}$ temperatures, albeit only the cast alloy exhibits the MT during stress-free thermal cycling. A bias stress during thermal cycling was required to bring about measurable shape memory behavior for the deformation-processed material. The yield stress of the $\mathrm{Nb}$ -
Fig. 5 Strain-temperature responses for thermal cycling under constant stress for a the cast alloy and $\mathbf{b}$ the deformation-processed alloy. The single and double arrows depict the slopes during cooling and heating, respectively. The symbols are defined within the text
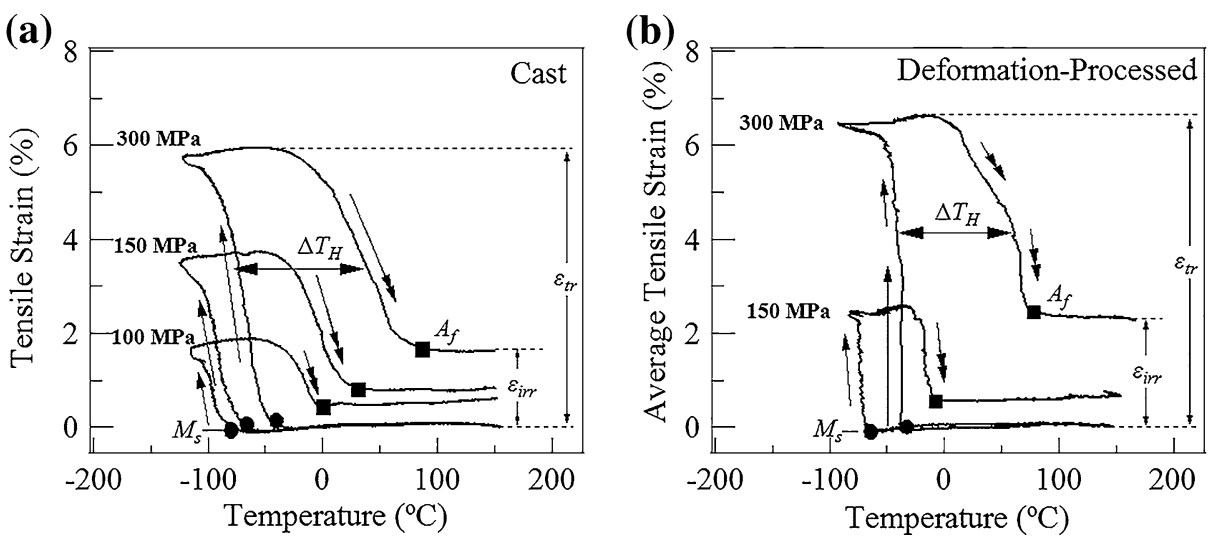
Fig. 6 Characteristics parameters a forward and reverse transformation temperature intervals and b thermal hysteresis and recovery ratio for different levels of bias stress in Fig. 5. The symbols are defined within the text

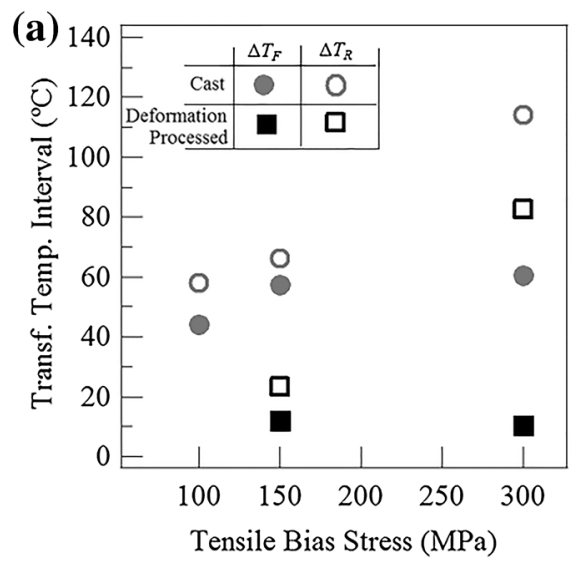

rich fibers has been estimated around $200 \mathrm{MPa}$ [23], and thus, impacts on the metrics become apparent when the bias load is increased from 150 to $300 \mathrm{MPa}$. There is a drastic increase in $A_{\mathrm{f}}$ for both alloys. Consequently, the reverse transformation temperature intervals $\Delta T_{\mathrm{R}}$ increase starkly (by comparison, the forward transformation intervals $\Delta T_{\mathrm{F}}$ are relatively consistent). Though the cast material exhibits the largest hysteresis levels, the most marked increase in hysteresis with bias load occurs for the deformation-processed material. For both materials, a maximum is apparent in the recovery ratios and the ratios drop with that increase in hysteresis.

In as-cast materials, microstructure analysis shows that the matrix regions are apparently free of the $\mathrm{Nb}$-rich phase, whereas the phase is dispersed throughout the matrix as fibers in the deformation-processed materials. For the deformation-processed composite-like microstructure, the $\beta$-fibers exist as closely spaced reinforcements within the matrix. Hence, an external bias load is required to facilitate the one-way shape memory response and a measurable strain-temperature $(\varepsilon-T)$ response. The composite microstructure will increase the interfaces between $\mathrm{NiTi}(\mathrm{Nb})$ and $\beta-\mathrm{Nb}$ phases [20] and which could act to increase the dislocation density associated with the strength mismatch between $\beta$-Nb fibers and matrix [35]. During straining throughout the forward martensitic transformation (MT), the Nb-rich fibers can have a strong coupling with the $\mathrm{NiTi}(\mathrm{Nb})$ matrix $[37,38]$. Coupled internal stresses can be created between the fibers and the $\mathrm{NiTi}(\mathrm{Nb})$ matrix during the forward MT, and thus, an "internal-stress affected zone" can exist in the local vicinity of the fibers [36]. We envisage that the $\operatorname{NiTi}(\mathrm{Nb})$ matrix regions within the cellular cast microstructure can readily undergo the MT with the variant morphology dictated by the external stress. The influence of the eutectic microconstituent will likely be relegated to inconsequential localized volume fractions adjacent to the microconstituent boundaries. On the other hand, the "internal-stress affected" zones can dictate the MT variant morphology due to the closely spaced fibers in the composite arrangement of the deformation-processed material. Those hypothesized contrasts are the focus of ongoing research efforts. The contrasts are the basis for the following correlations between the strain-temperature segments and energetic contributions.

The slopes of the heating and cooling $\varepsilon-T$ curves for cast and deformation-processed materials underscore the impact of the differential microconstituent morphologies on the energetics of the martensitic phase transformation. The $\varepsilon-$ $T$ cooling and heating curves exhibit differential slopes with increasing tensile bias load. The heating and cooling $\varepsilon-T$ curves of the cast material exhibit a single slope, and thus a single stage at each stress level. When the heating and cooling $\varepsilon-T$ segments exhibit similar slopes at the lower bias stresses, the responses are in accordance with crystallographic reversibility [43, 44]. At the highest stresses, the heating and cooling curves for the cast or deformation-processed alloy no longer exhibit equivalent slopes. The slope of the cooling curve reflects continuous undercooling, which overcomes elastic energy that otherwise resists the forward MT [43]. The cooling curves exhibit the steepest slopes for the deformation-processed material, and hence, elastic energy storage is not predominant. During the initial stage in the cooling curves for the process alloy, elastic energy storage is compromised which apparently facilitates the nearly isothermal growth of martensite [43].

The thermal hysteresis is directly related to energy that is irreversibly dissipated during the MT [43-45]. Stored elastic energy can be irreversibly dissipated during the forward MT due to plastic deformation and thus the hysteresis widens, as the stored elastic energy is not available to assist the reverse transformation $[13,43,46]$. The drastic increase in $A_{\mathrm{f}}$, for both cast and deformation-process alloys, reflects a martensite stabilization effect [4, 10, 40-42]. Martensite can be stabilized when it is pinned or heavily dislocated such that the reverse transformation requires a higher driving force [41, 42, 47]. It has been 
postulated that the $\beta$-phase can "lock" the martensitic phase in NiTiNb alloys [48]. For the current results, the reverse transformation temperatures must increase greatly beyond the $A_{\mathrm{f}}$ temperature for stress-free thermal cycling, as well as the temperatures at the lowest bias stress levels.

The absences of a corresponding isothermal stage in the heating $\varepsilon-T$ curves reveal differential transformation paths for the forward versus reverse MTs for the deformationprocessed alloys. Differential transformation paths can suggest non-thermoelastic MTs occur at the higher stress levels $[44,49,50]$. The stark differential between forward and reverse transformation temperatures intervals can further point to a non-thermoelastic MT for both deformationprocessed NiTiNb alloys as well as cast alloys [43, 44, 49, 50]. The widening thermal hysteresis and diminished recovery ratio at the highest bias stress imply marked irreversibility that is common for non-thermoelastic MTs.

\section{Conclusions}

This comparative study of load-biased thermal cycling of cast and deformation-processed NiTiNb alloys aimed to correlate differential strain-temperature responses with microstructure contrasts. The current findings support the following conclusions.

- Close spacing between the aligned Nb-rich fiber reinforcements in deformation-processed alloys brings about a microstructure constraint that can suppress the thermal-induced MT. A minimum biasing stress overcomes the constraint.

- In the processed microstructure, the elastic energy storage is relaxed. At the highest levels of constant stress, the strain-temperature response of the deformation-processed alloys reflects that the forward and reverse MTs in processed alloys take place in two stages. A single stage is observed in the MTs in the cast alloys. The slopes of the strain-temperature curves are steepest, and the initial stage is seemingly isothermal for the processed alloy.

- The deformation-processed as well as the cast microstructures facilitate a stabilization effect that impacts the reverse transformation by increasing $A_{\mathrm{f}}$ and diminishes the recovery ratio. The slopes of the heating and cooling segments are not equivalent. Plastic deformation associated with $\mathrm{Nb}$-rich fibers can readily occur at the $300 \mathrm{MPa}$ bias stress level, considering that it exceeds the reported flow stress of $\mathrm{Nb}$. Hence, the transformation may become non-thermoelastic.

Acknowledgments This study has been supported by the MidAtlantic Universities Transportation Center (MAUTC) Pooled Research Program issued by the Research and Innovative Technology
Administration of the US DOT (Grant No. DTRT12-G-UTC03). The authors would like to thank Marius Schraff (Eidgenössische Technische Hochschule, Zurich, Switzerland) and Xiaoning Xi (Penn State) for their help in acquiring AFM images.

\section{References}

1. Duerig T, Melton K (1989) Wide hysteresis NiTiNb alloys. In: European Symposium on Martensitic Transformations: EDP Sciences, p. 191-198

2. Melton K, Proft J, Duerig T (1988) Wide hysteresis shape memory alloys based on the Ni-Ti-Nb system. In: Proceedings of the MRS International Meeting on Advanced Materials, p. 165-170

3. Zhang C, Wang Y, Chai W, Zhao L (1991) The study of constitutional phases in a $\mathrm{Ni}_{47} \mathrm{Ti}_{44} \mathrm{Nb}_{9}$ shape memory alloy. Mater Chem Phys 28:43-50

4. Zhang CS, Zhao LC, Duerig TW, Wayman CM (1990) Effects of deformation on the transformation hysteresis and shape memory effect in a $\mathrm{Ni}_{47} \mathrm{Ti}_{44} \mathrm{Nb}_{9}$ alloy. Scr Metall Mater 24:1807-1812

5. Zhao L, Duerig T, Justi S, Melton K, Proft J, Yu W et al (1990) The study of niobium-rich precipitates in a $\mathrm{Ni}-\mathrm{Ti}-\mathrm{Nb}$ shape memory alloy. Scr Metall Mater 24:221-225

6. Zhao L, Zhang C, Cai W (1994) The study of the deformed stress-induced martensite and its stability in a Ni-Ti-Nb alloy. Shape Memory Materials, p. 25-28

7. Zhao L, Cai W (1996) The interface structure and stability of deformation-induced martensite in a Ni-Ti-Nb alloy with wide hysteresis. In: International Conference on Displacive Phase Transformations and Their Applications in Materials Engineering, p. 93-100

8. Zheng Y, Cai W, Luo Y, Zhao L (1997) Effects of heat treatment on tensile properties and shape memory effects of ni-ti-nb alloy. Trans Nonferrous Met Soc China (China) 7:92-96

9. Zhao LC (2000) Study of Ti-Ni-Nb shape memory alloys with a wide hysteresis. Mater Sci Forum 327-328:23-30

10. Zhao X, Yan X, Yang Y, Xu H (2006) Wide hysteresis NiTi(Nb) shape memory alloys with low $\mathrm{Nb}$ content (4.5at.\%). Mater Sci Eng A 438-440:575-578

11. Piao M, Miyazaki S, Otsuka K (1992) Characteristics of deformation and transformation in $\mathrm{Ti}_{44} \mathrm{Ni}_{47} \mathrm{Nb}_{9}$ shape memory alloy. Mater Trans JIM 33:346-353

12. Piao M, Miyazaki S, Otsuka K, Nishida N (1992) Effects of Nb addition on the microstructure of Ti-Ni alloys. Mater Trans JIM 33:337-345

13. Piao M, Otsuka K, Miyazaki S, Horikawa H (1993) Mechanism of the $\mathrm{A}_{\mathrm{s}}$ temperature increase by pre-deformation in thermoelastic alloys. Mater Trans JIM 34:919-929

14. Choi E, Cho B-S, Park J, Park K (2011) Inducing recovery stress of NiTiNb SMA wires using heat of hydration for confining concrete. J Intell Mater Syst Struct 22:1949-1957

15. Choi E, Nam T, Chung Y, Kim Y, Lee S (2012) Behavior of $\mathrm{NiTiNb}$ SMA wires under recovery stress or prestressing. Nanoscale Res Lett 7:66-70

16. Cui D, Zhang Y, Guan P (2012) Research progress of smart concrete structures reinforced by shape memory alloy. Appl Mech Mater 226:1157-1160

17. Dommer K, Andrawes B (2012) Thermomechanical characterization of NiTiNb shape memory alloy for concrete active confinement applications. J Mater Civil Eng 24:1274-1282

18. Sherif M, Ozbulut O, Lanba A, Hamilton RF (2014) Self-posttensioning for concrete beams using shape memory alloys. In: ASME 2014 conference on smart materials, adaptive structures and intelligent systems: American Society of Mechanical Engineers, p. V002T04A14-VT04A14 
19. Wang EM, Hong QH, Ni ZM, Han J (2014) Influence of processing state on recovery stress in NiTiNb shape memory alloy. Adv Mater Res 875:1525-1528

20. Bao Z-Z, Guo S, Xiao F, Zhao X-Q (2011) Development of $\mathrm{NiTiNb}$ in situ composite with high damping capacity and high yield strength. Prog Nat Sci 21:293-300

21. Xiao F, Ma G, Zhao X, Xu H, Jiang H, Rong L (2007) A novel TiNiNb shape memory alloy with high yield strength and high damping capacity, p. 64232L-L-6

22. Zhu R, Tang G, Shi S, Fu M (2013) Effect of electroplastic rolling on deformability and oxidation of NiTiNb shape memory alloy. J Mater Process Technol 213:30-35

23. Otsuka K, Wayman CM (1998) Shape memory materials. Cambridge University Press, Cambridge

24. Prima SB, Tret'yachenko LA, Petyukh VM (1996) Phase relations in the Ti-TiNi-NbNi-Nb region of the ternary system Ti-NbNi. Powder Metall Met Ceram 34:155-160

25. Siegert W, Neuking K, Mertmann M, Eggeler GF (2002) Influence of $\mathrm{Nb}$ content and processing conditions on microstructure and functional properties of NiTiNb shape-memory alloys. Mater Sci Forum 394-395:361-364

26. Ying C, Hai-chang J, Li-jian R, Li X, Xin-qing Z (2011) Mechanical behavior in NiTiNb shape memory alloys with low $\mathrm{Nb}$ content. Intermetallics 19:217-220

27. Wang M, Jiang M, Liao G, Guo S, Zhao X (2012) Martensitic transformation involved mechanical behaviors and wide hysteresis of NiTiNb shape memory alloys. Prog Nat Sci 22:130-138

28. Shi H, Frenzel J, Schryvers D (2013) EM, characterization of precipitates in as-cast and annealed $\mathrm{Ni45.5Ti45.5 \textrm {Nb } 9}$ shape memory alloys. Mater Sci Forum 738-739:113-117

29. Schryvers D, Shi H, Martinez GT, Van Aert S, Frenzel J, Van Humbeeck J (2013) Nano-and microcrystal investigations of precipitates, interfaces and strain fields in Ni-Ti-Nb by various TEM techniques. Materials Science Forum, Trans Tech Publ, Zürich, pp 65-71

30. Shi H, Frenzel J, Martinez GT, Van Rompaey S, Bakulin A, Kulkova $\mathrm{S}$ et al (2014) Site occupation of $\mathrm{Nb}$ atoms in ternary $\mathrm{Ni}-\mathrm{Ti}-\mathrm{Nb}$ shape memory alloys. Acta Mater 74:85-95

31. Tosetti JP, da Silva GA, Otubo J (2014) Microstructure evolution during fabrication of Ni-Ti-Nb SMA wires. Materials Science Forum, Trans Tech Publ, Zürich, pp 534-537

32. Kim HY, Jinguu T (2011) Nam T-h, Miyazaki S. Cold workability and shape memory properties of novel $\mathrm{Ti}-\mathrm{Ni}-\mathrm{Hf}-\mathrm{Nb}$ hightemperature shape memory alloys. Scripta Mater 65:846-849

33. Yan Y, Jin W, Li XW (2012) Texture development in the $\mathrm{Ni}_{47}$ $\mathrm{Ti}_{44} \mathrm{Nb}_{9}$ shape memory alloy during successive thermomechanical processing and its effect on shape memory and mechanical properties. Metall Mater Trans A 44:978-989

34. Yin X, Mi X, Li Y, Gao B (2012) Microstructure and properties of deformation processed polycrystalline $\mathrm{Ni}_{47} \mathrm{Ti}_{44} \mathrm{Nb}_{9}$ Shape memory alloy. J Mater Eng Perform 21:2684-2690
35. Tong YX, Jiang PC, Chen F, Tian B, Li L, Zheng YF et al (2014) Microstructure and martensitic transformation of an ultrafinegrained TiNiNb shape memory alloy processed by equal channel angular pressing. Intermetallics 49:81-86

36. Liu Z, Cui L, Liu Y, Jiang D, Jiang J, Shi X et al (2014) Influence of internal stress coupling on the deformation behavior of NiTi$\mathrm{Nb}$ nanowire composites. Scripta Mater 77:75-78

37. Hao SJ, Cui LS, Wang YD, Jiang DQ, Yu C, Jiang J et al (2011) The ultrahigh mechanical energy-absorption capability evidenced in a high-strength NbTi/NiTi nanocomposite. Appl Phys Lett 99:024102

38. Hao S, Cui L, Jiang D, Han X, Ren Y, Jiang J et al (2013) A transforming metal nanocomposite with large elastic strain, low modulus, and high strength. Science 339:1191-1194

39. Kusagawa M, Nakamura T, Asada Y (2001) Fundamental deformation and recovery behaviors of $\mathrm{Ni}-\mathrm{Ti}-\mathrm{Nb}$ shape memory alloy. JSME Int J A 44:57-63

40. Lin HC, Wu SK, Chou TS, Kao HP (1991) The effects of cold rolling on the martensitic transformation of an equiatomic TiNi alloy. Acta Metall Mater 39:2069-2080

41. Liu Y, Galvin SP (1997) Criteria for pseudoelasticity in nearequiatomic NiTi shape memory alloys. Acta Mater 45:4431-4439

42. Liu Y, Favier D (2000) Stabilisation of martensite due to shear deformation via variant reorientation in polycrystalline NiTi. Acta Mater 48:3489-3499

43. Hamilton RF, Sehitoglu H, Chumlyakov Y, Maier HJ (2004) Stress dependence of the hysteresis in single crystal NiTi alloys. Acta Mater 52:3383-3402

44. Salzbrenner RJ, Cohen M (1979) On the thermodynamics of thermoelastic martensitic transformations. Acta Metall 27:739-748

45. Lanba A, Hamilton R (2004) Elastic and irreversible energies of a two-stage martensitic transformation in NiTi utilizing calorimetric measurements. Metall Mater Trans A 45:2732-2740

46. Shi H, Pourbabak S, Van Humbeeck J, Schryvers D (2012) Electron microscopy study of Nb-rich nanoprecipitates in $\mathrm{Ni}-\mathrm{Ti}-$ $\mathrm{Nb}$ and their influence on the martensitic transformation. Scripta Mater 67:939-942

47. Liu Y, Liu Y, Van Humbeeck J (1998) Two-way shape memory effect developed by martensite deformation in NiTi. Acta Mater 47:199-209

48. Gordon RF (2011) Method for producing strain induced austenite. US Patent No 7,988,722 B2

49. Ling HC, Owen WS (1981) A model of the thermoelastic growth of martensite. Acta Metall 29:1721-1736

50. Olson GB, Cohen M (1975) Thermoelastic behavior in martensitic transformations. Scr Metall 9:1247 